Revista Latinoamericana de la Papa 22 (2): 10 - 32

ISSN: $1853-4961$

http://www.papaslatinas.org/revista.html

\title{
Marcadores moleculares asociados a genes de resistencia para Globodera sp. y virus PVY en papa (Solanum tuberosum L.)
}

\author{
J. Gabriel ${ }^{1 / *}$, A. Terán ${ }^{2}$, S. Veramendi ${ }^{3}$, M. Baldelomar², G. Main ${ }^{3}$
}

Recibido: 01/10/2018

Aceptado: 06/11/2018

Accesible en línea: Diciembre de 2018

\section{Resumen}

Las enfermedades causadas por virus y nematodos reducen los rendimientos y la calidad del tubérculo semilla en los cultivos de papa de todo el mundo, por lo que se toman diversas medidas y esfuerzos en investigación para combatir estas enfermedades. Esta investigación se planteó con el objetivo de validar tres marcadores moleculares asociados a genes de resistencia al nematodo quiste (Globodera rostochiensis y G. pallida) y al virus PVY en cultivares mejorados de papa. El estudio se realizó en condiciones de laboratorio e invernadero. En laboratorio la PCR permitió evaluar la presencia de los genes de resistencia a través del marcador RySC3 para resistencia al virus PVY y los marcadores HC y Gro 1-4 para resistencia a $G$. pallida y $G$. rostochiensis respectivamente. En invernadero el análisis de resistencia y/o susceptibilidad se determinó a través de la absorbancia (método DASELISA) y severidad para el virus PVY y la tasa de multiplicación en raíz (TMR) para el nematodo del quiste. Se verificó que el alelo para el marcador RySC3 está co-localizado con el gen $R y_{a d g}$ para resistencia a PVY, que fue observado en todos los cultivares a excepción de Huaycha. Por otro lado el alelo para el marcador HC que co-localiza con el gen/QTL RGp5-vrnHC para resistencia a G. pallida, se observó en 14 de las 20 cultivares evaluados, es decir el $70 \%$ mostraron el alelo de resistencia y el alelo para el marcador Gro1-4 que co-localiza con el gen Grol-4 para resistencia a G. rostochiensis se observó en 7 de los 20 cultivares, es decir el $35 \%$ de los cultivares mostraron el alelo de resistencia a G. rostochiensis.

Palabras claves adicionales: Enfermedades, absorbancia, alelo, severidad, asociación.

\footnotetext{
Autor para correspondencia: E mail: julio.gabriel@unesum.edu.ec/j.gabriel@proinpa.org Fundación PROINPA. Actualmente Universidad Estatal del Sur de Manabí, Jipijapa, Manabí, Ecuador. Facultad de Biología, Universidad Mayor de San Simón, Cochabamba, Bolivia. Fundación PROINPA, Casilla 4285, Cochabamba, Bolivia.
} 


\section{Molecular markers for Globodera rostochiensis, G. pallida and PVY virus in potato (Solanum tuberosum L.)}

\section{Summary}

The diseases caused by viruses and nematodes reduce the yields and quality of the seed tuber in potato crops throughout the world, which is why various measures and research efforts are taken to combat these diseases. This research was aimed at validating three molecular markers associated with resistance genes to the cyst nematode (Globodera rostochiensis and G. pallida) and the PVY virus in improved potato cultivars. The study was conducted under laboratory and greenhouse conditions. In the laboratory the PCR allowed to evaluate the presence of the resistance genes through the RySC3 marker for resistance to the PVY virus and the markers HC and Gro 1-4 for resistance to G. pallida and $G$. rostochiensis respectively. In the greenhouse, the analysis of resistance and / or susceptibility was determined through the absorbance (DAS-ELISA method) and severity for the PVY virus and the root multiplication rate (TMR) for the cyst nematode. It was verified that the allele for the RySC3 marker is co-localized with the Ryadg gene for resistance to PVY, which was observed in all cultivars with the exception of Huaycha. On the other hand, the allele for the HC marker that co-localizes with the gene / QTL RGp5vrnHC for resistance to $\mathrm{G}$. pallida, was observed in 14 of the 20 cultivars evaluated, that is, $70 \%$ showed the resistance allele and the allele for the marker Gro1-4 that co-localizes with the gene Gro1-4 for resistance to G. rostochiensis was observed in 7 of the 20 cultivars, that is to say $35 \%$ of the cultivars showed the allele of resistance to G. rostochiensis.

Additional keywords: Diseases, absorbance, allele, severity, association.

\section{Introducción}

Bolivia es parte de los 15 países más megadiversos del mundo. La diversidad de ecoregiones y la presencia imponente de la Cordillera de los Andes, hace que estas zonas sean ricas en diversidad de alturas, climas y taxas de especies. $\mathrm{La}$ mayor diversidad de papas en el mundo se encuentra en su lugar de origen: el altiplano de los Andes, principalmente en Perú y Bolivia. Desde hace ocho mil años la papa es el alimento básico de las poblaciones del altiplano (Gabriel et al., 2011; Devaux y Ordinola, 2012).

Las especies silvestres que hoy en día habitan en las zonas altoandinas de América del Sur dieron origen a la papa cultivada. Según Hawkes (1978), estas especies han jugado durante más de diez mil años un papel clave en el desarrollo de los cultivares nativos y silvestres con resistencia a estreses bióticos y abióticos.
Estas especies silvestres hoy día representan un gran reservorio y caudal de genes adicionales de recursos genéticos de la papa (Chávez, 2007).

Por tanto la biodiversidad de la papa no está restringida a especies cultivadas sino que se relacionan con especies silvestres. La papa tiene más especies silvestres afines que cualquier otro cultivo. En Bolivia la biodiversidad de la papa abarca más de 1500 cultivares nativos y ocho especies cultivadas: Solanum tuberosum subsp. andígena, S. stenotomum, S. $x$ ajanhuiri, $S$. x curtilobum, S. goniocalyx, S. $x$ juzepczukii, $S . x$ chaucha y $S$. phureja, siendo la más cultivada $S$. tuberosum subsp. andígena. Además de estas ocho especies cultivadas se han identificado 39 especies silvestres (Gabriel et al., 2011). 
Este tubérculo es cultivado en pequeñas superficies de tierra, ocupa el primer lugar entre los tubérculos cultivados con una superficie aproximada de 125 a 130.000 hectáreas de cultivo (Coca, 2012) e involucra aproximadamente a 200.000 agricultores en su producción, que son el 30 a $40 \%$ del total de agricultores del país (Gabriel et al., 2011). Es la principal fuente de alimentación e ingresos en Bolivia y se conoce que 114 municipios del país han priorizado la papa (Zeballos et al., 2009).

A pesar de la gran importancia que tiene en el país, la producción y productividad es baja, con un rendimiento promedio de $6 \mathrm{t} / \mathrm{ha}$, aunque en algunas zonas como los valles interandinos y los valles mesotérmicos de Cochabamba y Santa Cruz, los rendimientos son mayores a 10 t/ha, mientras que países como Estados Unidos y la Unión Europea han alcanzado rendimientos superiores a los $50 \mathrm{t} / \mathrm{ha}$. Las razones por las cuales se da esta situación son múltiples, desde las condiciones en las que se cultiva, calidad de la semilla, cultivo en zonas montañosas que dificultan la mecanización etc., por citar algunas pero además, se tiene la presencia de plagas, enfermedades y condiciones del clima adversos (Gabriel et al., 2011).

Las enfermedades que afectan la producción de papa son diversas. Estrada (2000) menciona 25 virus, 38 hongos, 6 bacterias, 2 micoplasmas y un viroide; además de 68 especies de nematodos y 128 insectos-plaga, totalizando unos 266 patógenos y plagas.

Los nematodos del quiste son una plaga seria en algunas de las principales zonas de cultivo de papa. Originarios de la zona andina, se han diseminado a algunas regiones de clima templado y a las zonas altas de algunos lugares tropicales, donde reducen considerablemente los rendimientos. El ataque de los nematodos favorece las infecciones de las plantas por la marchitez bacteriana (Ralstonia solanacearum) y la marchitez por Verticillium (CIP, 1996).

Por otra parte el virus PVY es el segundo más importante de la papa. Es perpetuado por tubérculos infectados $\mathrm{y}$ transmitido por áfidos en forma no persistente. Las pérdidas en el rendimiento pueden llegar hasta $80 \%$ (CIP, 1996). Su impacto en la industria y el cultivo de papa es de grandes dimensiones, así como los esfuerzos en investigación que se realizan para combatir estas enfermedades.

Diversas medidas han sido tomadas a lo largo de los años para reducir los daños causados por estos patógenos. Principalmente el incremento en el uso de plaguicidas sintéticos, los cuales, a partir del desarrollo de su industria en la década de 1940 han representado durante más de 60 años la base fundamental del combate de las plagas, llegando a ocasionar además de efectos nocivos en los humanos, un desequilibrio en los agroecosistemas andinos contaminando suelo, agua, alimentos y afectando la biodiversidad. Asimismo es importante señalar que a nuestro país ingresan legalmente e ilegalmente plaguicidas que están prohibidos y/o restringidos en otros países de la región por ser altamente tóxicos (Cervantes, 2010).

Por tanto con el fin de reducir la aplicación de agroquímicos en la producción agrícola de papa, se propone el mejoramiento genético vegetal, que permitiría la obtención y selección de genotipos superiores; estos genotipos lograrían una mayor producción, tanto en calidad como en cantidad de los cultivos; una resistencia a plagas y enfermedades, y una disminución de la contaminación de 
suelos durante el proceso de producción (Alarcón, 2008).

En los últimos años la tecnología de los marcadores moleculares se volvió una herramienta indispensable para apoyar los programas de mejoramiento convencional para selección varietal, que en general llevan mucho tiempo ya que están basados en el cruzamiento de cultivares con caracteres valiosos esperando obtener cultivares con atributos de los progenitores que se complementen, evaluadas en campo (Mendoza, 2008). Por medio de marcadores moleculares se puede obtener información acerca de la existencia de determinado alelo, segmento cromosómico o cromosoma completo o de una secuencia particular de ADN en una determinada muestra, accesión o población, bien porque el marcador utilizado es parte del gen de interés o porque está genéticamente ligado al mismo (Ford-Lloyd, 2001), lo cual facilita la selección de los genes de interés para su posterior introducción a las cultivares, ya que la mayoría de los rasgos importantes en los cultivos como producción, calidad y formas de resistencia a enfermedades son controlados por genes que pueden asociarse a marcadores moleculares (Mosquera et al., 2008).

La validación de estos marcadores moleculares permitirá acelerar el proceso de mejoramiento genético a través de la identificación de algunos genes de interés en papas bolivianas y permitir el cruzamiento de modo más efectivo (Alarcón, 2008).
El objetivo de la investigación fue validar tres marcadores moleculares asociados a genes de resistencia al nematodo quiste (Globodera rostochiensis y G. pallida) y al virus PVY en cultivares mejorados de papa.

\section{Materiales y Métodos}

\section{Ubicación}

La investigación se llevó a cabo en la Fundación para la Promoción e Investigación de Productos Andinos (PROINPA), ubicado en el municipio de El Paso dentro de la provincia Quillacollo, que corresponde a la región de los valles secos interandinos a 2500 msnm.

\section{Material biológico}

Se utilizaron 20 cultivares de papa tetraploides (Tabla 1). Los cultivares utilizados en los ensayos fueron proporcionados por la Fundación PROINPA, seleccionados de una lista de nuevos cultivares, con resistencia a plagas y enfermedades, que fueron evaluados en campo previamente (Gabriel, 2010; Gabriel et al., 2011). Para las reacciones de PCR se utilizaron como controles resistentes $(+)$ los cultivares nativos: Papa Rosa (adg); Pinta Boca (stn) y Wallpa Ningri (stn), para los marcadores RySC3, HC, y Gro 1-4 respectivamente.

Para el ensayo con nematodos se utilizó como inóculo, sustrato infestado con ambas especies del nematodo del quiste (G. rostochiensis y G. pallida) y para el ensayo con el virus PVY, se utilizó plantas del cultivar Huaycha infectadas con el virus obtenidas en campo. 
Tabla 1. Lista de cultivares evaluados y genealogía

\begin{tabular}{|c|c|c|}
\hline \multirow{2}{*}{ Cultivar } & \multicolumn{2}{|c|}{ Genealogía } \\
\hline & Madre & Padre \\
\hline Aurora & India & Huaycha \\
\hline Chota Nawi & 380073.2 & {$[($ sto x pls $)]$} \\
\hline Desireé & Urgenta & Depesche \\
\hline India & US 136.6 & {$[3345 \mathrm{D}(1) \times 2288 \mathrm{~A}(2)]$} \\
\hline Isabel & $82-222-2$ & Jaspe \\
\hline Jaspe & (sto x pls) & (tbr x phu) \\
\hline Keila & $82-222-2$ & Jaspe \\
\hline Morita & $82-222-2$ & India \\
\hline P'alta Chola & India & Robusta \\
\hline Pafrita & Perla & Desirée \\
\hline Pinker & Solanum fendleri & Desirée \\
\hline Puyjuni Imilla & India & Huaycha \\
\hline Robusta & (tbr x adg) & tbr \\
\hline Rosada & (iop-phu) & Sani Imilla (adg) \\
\hline Runa Toralapa & tbr (I-1058) & $\operatorname{adg}(700764)$ \\
\hline Salomé & India & $($ phu + gon $)$ \\
\hline Victoria & $86-40-3$ & Puquina (720049) \\
\hline Violeta & [Robusta x 82-3-5] & [Robusta x 82-3-5] \\
\hline Yungueñita & O.P. Yungay & \\
\hline Huaycha & \multicolumn{2}{|c|}{ S. andígena } \\
\hline
\end{tabular}

Fuente: Gabriel et al. (2011)

\section{Metodología}

Las pruebas en laboratorio realizadas para el análisis de co-localización de los marcadores moleculares con sus respectivos genes/QTLs de resistencia se hicieron en los siguientes pasos: Colecta del material biológico y extracción de ADN, cuantificación de ADN genómico, amplificación mediante PCR y cuantificación de ADN amplificado.

Se realizó la colecta de foliolos tiernos y sanos de plantas de todos los cultivares y se almacenaron $\mathrm{a}-20{ }^{\circ} \mathrm{C}$. Posteriormente se realizó la molida de las muestras con nitrógeno líquido a $-196^{\circ} \mathrm{C}$. $\mathrm{La}$ extracción del ADN de los 19 cultivares de papa y del cultivar Huaycha (control), se realizó según el protocolo CTAB $2 \mathrm{X}$ (hexadecil bromuro de trimetil amonio) de extracción de ADN de plantas (Doyle y Doyle, 1990).

La cuantificación de ADN total se realizó a partir de las muestras extraídas, mediante electroforesis en gel de Agarosa 
al 1\%. Para la cuantificación se utilizó: 8 $\mu \mathrm{L}$ de agua destilada, $1 \mu \mathrm{L}$ de $\mathrm{ADN}$ total y $1 \mu \mathrm{L}$ de tampón de cargado $(1 \mathrm{~mL}$ de tampón de cargado $+8 \mathrm{uL}$ de syber green). Se depositaron las muestras en los pocillos del gel, colocando en un pocillo el marcador de peso molecular de 10.000 pares de bases (bp) para comparar la intensidad de las bandas y se aplicó la corriente $(5 \mathrm{~V} / \mathrm{cm})$. Finalmente se colocó el gel sobre la fuente de luz ultravioleta para fotografiar e interpretar los resultados.
En base a los valores de concentración obtenidos en la cuantificación se realizaron diluciones del $\mathrm{ADN}$ de cada muestra, para obtener concentraciones de ADN molde de $4 \mathrm{ng} / \mu \mathrm{l}$ para cada cultivar, conservados a $-20^{\circ} \mathrm{C}$.

Se realizó una PCR en gradiente para encontrar la temperatura óptima de anillamiento, probando un rango de temperaturas de $50-60^{\circ} \mathrm{C}$ para los tres marcadores (Tabla 2), siendo estos los rangos de temperatura usados por Gebhardt et al. (2006), Ottoman et al. (2009) y Guzmán (2010) (Tabla 3).

Tabla 2. Ubicación de los genes de resistencia en el respectivo cromosoma y el marcador usado de acuerdo al patógeno estudiado.

\begin{tabular}{ccccc}
\hline Patógeno & Gen resistente & Cromosoma & Marcador & Referencia \\
\hline Globodera pallida & RGp5-vrnHC & V & HC & Sattarzadeh et al. (2006) \\
\hline Globodera rostochiensis & Gro 1-4 & VII & Gro1-4 & Gebhardt et al. (2006) \\
\hline PVY & Ryadg & XI & RySC3 & Gebhardt et al. (2006)
\end{tabular}

Tabla 3. Análisis con los siguientes marcadores moleculares y las secuencias de los primers usados para amplificar dichos marcadores. Temperaturas de hibridación (Tm) usadas en PCR, junto con el tamaño del fragmento esperado.

\begin{tabular}{lllccc}
\hline Marcador & & \multicolumn{1}{c}{ Secuencias } & $\begin{array}{c}\text { Longitud del } \\
\text { producto }(\mathbf{p b})\end{array}$ & Tm $\left({ }^{\circ} \mathbf{C}\right)$ & $\begin{array}{c}\text { Tipo de } \\
\text { marcador }\end{array}$ \\
\hline \multirow{2}{*}{ HC } & f & ACACCACCTGTTTGATAAAAAACT & 276 & 58 & PCR \\
& r & GCCTTACTTCCCTGCTGAAG & & & \\
Gro1-4 & f & TCTTTGGAGATACTGATTCTCA & 602 & 60 & PCR \\
& r & CGACCTAAAATGAAAAGCATCT & & & \\
RYSC3 & f & ATA CAC TCA TCT AAA TTT GAT GG & 320 & 58 & SCAR \\
& r & AGG ATA TAC GGC ATC ATT TTT CCG A & & & \\
\hline
\end{tabular}

Forward primer (f), Reverse primer (r)

La composición y concentración de las mezclas son detallas en la Tabla 4. 
Tabla 4. Composición y concentración de mezclas.

Mix 1

\begin{tabular}{ccc}
\hline Reactivos stock & Final & $\mathbf{7} \boldsymbol{\mu l}$ \\
\hline Tampón PCR 10X & $1 \mathrm{X}$ & $1 \mu \mathrm{l}$ \\
dNTPs $2 \mathrm{mM} \mathrm{c/u}$ & $0.2 \mathrm{mM} \mathrm{c} / \mathrm{u}$ & $1 \mu \mathrm{l}$ \\
Iniciador directo y reverso (10pmol/ $\mu \mathrm{l}$ cada uno) & $1 \mathrm{pmol} / \mu \mathrm{l}$ & $0.8 \mu \mathrm{l}$ \\
$\mathrm{H}_{2} \mathrm{O}$ & & $4.2 \mu \mathrm{l}$ \\
$\mathrm{ADN}$ molde & $4 \mathrm{ng} / \mu \mathrm{l}$ & $3 \mu \mathrm{l}$ \\
\hline
\end{tabular}

Mix 2

\begin{tabular}{ccc}
\hline Stock & Final & $\mathbf{5} \boldsymbol{\mu l}$ \\
\hline H2O & $\mathrm{X}$ & $4.4 \mu \mathrm{l}$ \\
Tampón PCR 10X & $1 \mathrm{X}$ & $0.5 \mu \mathrm{l}$ \\
Taq polimerasa (añadir a último momento) & $0.025 \mathrm{U} / \mu \mathrm{l}$ & $0.1 \mu \mathrm{l}$ \\
\hline
\end{tabular}

Se prepararon los mix en un baño de hielo, para 22 muestras, incluyendo el control positivo (cultivar nativo) correspondiente a cada marcador y el control negativo de la reacción. Se tuvo en total $15 \mu \mathrm{L}$ de mezcla, de los cuales se distribuyó $5 \mu \mathrm{L}$ del mix 1 en los tubos PCR y se añadieron $3 \mu \mathrm{L}$ de ADN a cada tubo y $3 \mu \mathrm{L}$ de agua al control negativo.
Se añadieron $5 \mu \mathrm{L}$ del mix 2 y la taq polimerasa justo antes de repartir el mix 2. Finalmente se selló la placa PCR, se colocó al termociclador (modelo PTC100, MJ Research, Ramsey, Minnesota, USA) y se hizo correr el programa de amplificación (Tabla

5).

Tabla 5. Condiciones de ciclaje para cada marcador.

\begin{tabular}{ccc}
\hline Ciclo & Temperatura $\left({ }^{\mathbf{0}} \mathbf{C}\right)$ & Tiempo $(\mathbf{m i n})$. \\
\hline 1 ciclo & 94 & 5.0 \\
35 ciclos & 94 & 1.0 \\
& T de hibridación * & $45 \mathrm{seg}$. \\
& 72 & $45 \mathrm{seg}$. \\
1 ciclo & 72 & 5.0 \\
& 15 & 1.0 \\
\hline
\end{tabular}

$\mathrm{La} \mathrm{T}^{\circ}$ de hibridación específico para cada primer

\section{Cuantificación de productos PCR}

Los productos PCR se visualizaron en un gel de Agarosa al $1.8 \%$ (1.8 g de agarosa en $100 \mathrm{~mL}$ de TBE $1 \mathrm{X}$ ), se utilizaron 5 $\mu \mathrm{L}$ de la reacción y $0.5 \mu \mathrm{L}$ de tampón de cargado $(1 \mathrm{~mL}$ de tampón de cargado +8 $\mu \mathrm{L}$ de syber green) y fueron fotografiados 
con una cámara digital en el transiluminador con luz UV. Los fragmentos de ADN esperados se compararon con un marcador de peso molecular de $2500 \mathrm{pb}$.

\section{Pruebas en invernadero}

Previo a la siembra de todo el material, se realizó un tratamiento de los tubérculos con giberelina a 50 ppm $(0.05 \mathrm{~g}$ de ácido giberélico en polvo en $1 \mathrm{~L}$ de agua) durante 10 min para inducir la brotación.

Para evaluar la resistencia de las cultivares a los patógenos en invernadero, se utilizó un diseño completamente aleatorio en cada ensayo con un factor de variación, donde los 20 cultivares fueron los tratamientos con cuatro plantas/cultivar, correspondiendo a las unidades experimentales, haciendo un total de 80 plantas por ensayo (Gabriel et al., 2017).

\section{Resistencia a virus PVY}

En condiciones de invernadero, se realizó la siembra de los cultivares, incluyendo el control positivo y negativo. Se sembraron cuatro tubérculos por cultivar en distintas macetas de $2 \mathrm{~kg}$ con sustrato estéril compuesto por arena lama, chala de arroz y tierra vegetal en una proporción 1:1:1 respectivamente $\mathrm{y}$ fueron ubicados en mesones.

Se utilizó como inoculo material infectado con PVY recolectado de campo, con síntomas aparentes y se realizó un análisis serológico en laboratorio mediante DAS-ELISA (Double Antibody Sandwich), de acuerdo a lo descrito por Sosa et al. (1997). Una vez confirmada la presencia del virus se inocularon primeramente plantas del cultivar Huaycha, esto para la multiplicación del virus y para tener una cantidad suficiente del inoculo para el resto de los cultivares, las cuales se inocularon posteriormente.

Las plantas se inocularon a los 2 1/2 meses de la siembra, para esto se recolectaron muestras (foliolos) de las plantas del cultivar Huaycha en bolsas de plástico, se pesaron y se añadió un Buffer fosfato $0.01 \mathrm{M}$ con $\mathrm{pH} 8$ (Relación peso hojas: volumen buffer 1:3), para después molerlas y obtener clorofila. Con la mezcla del jugo de las muestras molidas, se realizó la inoculación mecánica por frotación a la superficie de los foliolos más grandes y sanos de las plantas en invernadero, pasándolas previamente con carborundum (abrasivo) para producir heridas que faciliten la iniciación de la infección en células potencialmente infectables (Sosa et al., 1997).

La evaluación de síntomas localizados y sistémicos en la planta se realizó durante dos días, a las tres semanas de inoculación (18 días) esto para que exista un aumento en la concentración del virus y los síntomas sean visibles. Se evaluaron los siguientes síntomas (Tabla $6)$.

Tabla 6. Síntomas en plantas de Solanum tuberosum infectadas con el virus PVY.

\begin{tabular}{cc}
\hline Síntomas localizados & Síntomas sistémicos \\
\hline Puntos necróticos & Encrespamiento \\
Mosaico leve & Acucharamiento cóncavo y convexo \\
Mosaico severo & Amarillamiento de ápices \\
\hline
\end{tabular}

Fuente: Coca (2010) 
Revista Latinoamericana de la Papa 22 (2): 10 - 32

http://www.papaslatinas.org/revista.html

\section{Resistencia al nematodo del quiste de la papa}

Se recolectó sustrato de suelo de parcelas infestadas con nematodos del quiste del municipio de Colomi, Cochabamba. Se realizó el lavado del sustrato de acuerdo al método modificado de Fenwick (González y Franco, 1993) para separar los quistes del mismo hasta obtener una concentración de 10 huevos/g de suelo.

Se realizó la prueba del bioensayo según la metodología descrita por Ortuño et al. (1994) para cada cultivar con cuatro repeticiones como sigue: Se llenaron las bolsas $(15 \times 20 \mathrm{~cm})$ con $400 \mathrm{~g}$ de mezcla de suelo orgánico compuesto por arena, chala de arroz y tierra vegetal en una proporción 1:1:1 respectivamente, desinfestada al calor, posteriormente se aumentaron $30 \mathrm{~g}$ de sustrato infestado con quistes (población inicial de quistes, $\mathrm{Pi}$ ), se mezcló y humedeció el suelo con 172 $\mathrm{mL}$ de agua corriente, que corresponde al $40 \%$ de humedad ya que la humedad excesiva causa pudriciones prematuras en la semilla. Se colocó un tubérculo brotado o un brote de un cultivar de papa en la bolsa, se tapó con el mismo sustrato y se cerró la bolsa. La bolsa se identificó con el nombre de la cultivar, el número de repetición y la fecha. Finalmente se colocaron las bolsas sembradas y cerradas en un lugar caliente $\left(20-25^{\circ} \mathrm{C}\right)$ y oscuro para evitar el crecimiento del follaje, dentro de una caja de cartón revestida interiormente con papel periódico, lo cual ayudó a conservar la temperatura. Se realizó un control diario usando un termómetro.

La inoculación de ambas especies de nematodos se realizó al momento de la siembra según el método del bioensayo descrito por Ortuño et al. (1994). Esto sin hacer distinción de especies de Globodera.

Se evaluaron los bioensayos 55 días después de la siembra, para determinar la presencia de quistes (Globodera spp.) (Ortuño et al., 1994). Se realizó la primera evaluación contando el número de hembras inmaduras que se observaron sobre el bolo radicular y evaluando el desarrollo de raíz en bueno, medio o bajo de acuerdo a la cantidad de raíz observada. El nivel de resistencia del clon se dio en base a la escala de evaluación que se indica en la Tabla 7 y en comparación con el cultivar Huaycha. La segunda evaluación se realizó un mes después de la primera contando la cantidad de huevos presentes en los quistes para determinar la viabilidad y densidad de la población final (Pf). De esta forma se calculó la relación Población final/Población inicial (Pf/Pi), donde valores $>1$ indican reproducción del nematodo (Jiménez-Pérez et al., 2007). 
Tabla 7. Escala de evaluación del nivel de resistencia.

\begin{tabular}{lll}
\hline \multicolumn{1}{c}{ Parámetro } & Escala & \multicolumn{1}{c}{ Reacción } \\
\hline & 0 & Resistente $(\mathrm{R})$ \\
Hembras inmaduras sobre & $1-15$ & Parcialmente resistente (PR) \\
la masa de suelo y raíces & $16-50$ & Moderadamente susceptible (MS) \\
& $>50$ & Susceptible (S) \\
& $<1.0$ & Resistente (R) \\
\cline { 2 - 3 } Tasa de multiplicación de & $1.0-3.7$ & Parcialmente resistente (PR) \\
huevos (ePf/ePi) & $3.8-7.0$ & Moderadamente susceptible (MS) \\
& $>7.0$ & Susceptible (S) \\
\hline
\end{tabular}

Fuente: González y Franco (1993)

\section{Evaluación 1}

Se evaluó el desarrollo de raíz en los bioensayos ya que las raíces son indispensables para la alimentación del nematodo, clasificando en una escala del 1-5 la cantidad de raíz observada, siendo 1 y 2: para un bajo desarrollo de raíz; 3: para un desarrollo intermedio y 4, 5: para un buen desarrollo de raíz. Posterior a esto se realizó el conteo de hembras inmaduras las cuales se encontraban adheridas a las raíces de los bioensayos.

\section{Evaluación 2}

Para la segunda evaluación se realizó los siguientes pasos:

Extracción de quistes de los bioensayos. Se realizó el lavado de $100 \mathrm{cc}$ de sustrato de cada bioensayo.

Separación de quistes con el método de flotación en gasolina descrito por CantoSáenz y González (1993).

Conteo de quistes, utilizando dos estereomicroscopios Reichert con un aumento de $1 \mathrm{X}$ a $6 \mathrm{X}$ con lente $10 \mathrm{X}$ cada uno. Se sacó el promedio de quistes existentes en cada cultivar y la viabilidad de los quistes se obtuvo a través de la trituración de 25 quistes por repetición de cada cultivar. Posteriormente, se realizó el conteo de huevos y juveniles de segundo estadío (J2) en dos estereomicroscopios, uno con un aumento de $1 \mathrm{X}$ a $6 \mathrm{X}$ con lente $10 \mathrm{X}$ de la marca Reichert; y el otro con un aumento de $1.5 \mathrm{X}$ a $4.5 \mathrm{X}$ con lente $15 \mathrm{X}$ de la marca Wolfe.

\section{Determinación de especies}

Para identificar las especies de Globodera se procedió al montaje de la región posterior del quiste realizando cortes perineales, de acuerdo a la metodología de González y Franco (1993). Se realizaron cortes de 10 quistes como mínimo, en dos repeticiones de seis cultivares, los cultivares Pafrita y Rosada que tuvieron en promedio la mayor cantidad de quistes, los cultivares Huaycha y Runa Toralapa que en promedio tuvieron una mediana cantidad de quistes y los cultivares P'alta Chola e India que en promedio tuvieron la menor cantidad de quistes en este estudio.

Una vez terminado el montaje, se procedió a contar las líneas entre el ano y la fenestra de cada muestra con la ayuda de un microscopio compuesto (10x20; 10x40), considerando que los quistes de Globodera pallida presentan menos de 14 líneas entre el ano y la fenestra y los 
quistes de G. rostochiensis más de 14 líneas.

\section{Variables de respuesta}

En el caso de nematodos fue la tasa de multiplicación (TM) que se calculó al obtener el promedio final de quistes $(\mathrm{Pf}) \mathrm{y}$ hembras inmaduras presentes en el bioensayo de cada cultivar. Para virus PVY se tomó en cuenta la presencia de síntomas localizados (ej. puntos necróticos, mosaico leve o mosaico severo) y sistémicos (ej. encrespamiento, acucharamiento, amarillamiento de ápices) en la planta y su reacción al test serológico DAS-ELISA de acuerdo al grado de absorbancia.

\section{Análisis Estadísticos}

El análisis de los datos se llevó a cabo con un análisis de varianza y comparación de medias utilizando el Proc GLM del SAS para cada una de las variables evaluadas (SAS Users Guide 2004), haciendo un previo análisis de normalidad y homogeneidad de varianzas (Gabriel et al., 2017).

Para el análisis de los nematodos debido a que se trataba de datos discretos que fueron respuestas numéricas resultado del proceso de conteo, se realizó una distribución (discreta) de Poisson para calcular las probabilidades asociadas a la variable aleatoria dentro de un intervalo continuo de tiempo o espacio (Hernández-González, 2007).

Los datos moleculares sobre presencia y ausencia del gen de resistencia se almacenaron en archivos con formato EXCEL para su posterior análisis estadístico.

Se aplicó un t-TEST para comparar las medias de niveles de resistencia en los cultivares que pertenecen a cada clase de marcadores (ausencia/presencia) en cada caso, utilizando Proc t-test del software SAS (SAS Users Guide, 2004).

\section{Resultados y discusión}

\section{Análisis con marcadores moleculares}

Utilizando el protocolo de extracción de Doyle y Doyle (1990) se obtuvo ADN de muy buena calidad (bandas netas, Figura 1). El ADN tuvo una concentración que fluctuó entre $40 \mathrm{ng} / \mu \mathrm{L}$ y $100 \mathrm{ng} / \mu \mathrm{L}$.

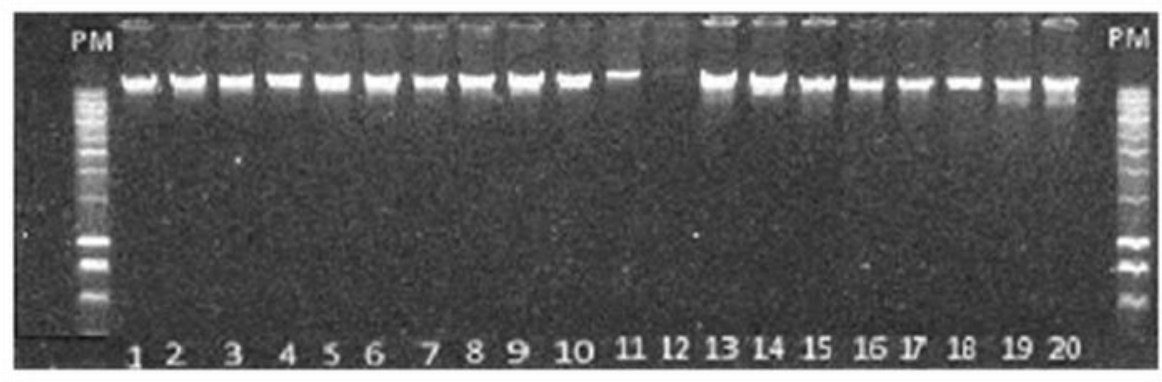

Figura 1. Cuantificación de ADN genómico. En la figura se observa el ADN de las 20 cultivares de papa. 1. Aurora, 2. Chota Nawi, 3. Desireé, 4. India, 5. Isabel, 6.Jaspe, 7. Keila, 8. Morita, 9. Pafrita, 10. P'alta Chola, 11. Pinker, 12. Puyjuni Imilla, 13. Robusta, 14. Rosada, 15. Runa Toralapa, 16. Salomé, 17. Victoria, 18. Violeta, 19. Yungueñita y 20. Huaycha 
Revista Latinoamericana de la Papa 22 (2): 10 - 32

http://www.papaslatinas.org/revista.html

ISSN: 1853-4961

Las pruebas de temperatura de hibridación realizadas en la PCR en gradiente determinaron que las temperaturas óptimas para los marcadores utilizados fueron los indicados en la Tabla 3 obteniendo los productos de amplificación esperados.

\section{Amplificación mediante PCR}

Una vez realizada la amplificación con los respectivos primers, se observó la presencia/ausencia de las bandas en los geles de electroforesis de cada uno de los marcadores en los cultivares estudiados (Tabla 8).

Tabla 8. Presencia/ausencia de alelos (QTL/genes) resistentes a PVY, G. pallida y $G$. rostochiensis en las cultivares evaluadas.

\begin{tabular}{|c|c|c|c|c|}
\hline \multirow{3}{*}{$\mathbf{N}^{\mathbf{o}}$} & \multirow{3}{*}{ Cultivares } & \multicolumn{3}{|c|}{ Marcadores moleculares } \\
\hline & & RYSC3 & $\mathrm{HC}$ & Gro 1-4 \\
\hline & & PVY & G. pallida & G. rostochiensis \\
\hline 1 & Aurora & + & + & - \\
\hline 2 & Chota Nawi & + & + & + \\
\hline 3 & Desireé & + & - & - \\
\hline 4 & Isabel & + & + & + \\
\hline 5 & Runa Toralapa & + & - & - \\
\hline 6 & Keila & + & + & + \\
\hline 7 & Morita & + & + & - \\
\hline 8 & Pafrita & + & - & - \\
\hline 9 & P'alta Chola & + & + & - \\
\hline 10 & Pinker & + & - & - \\
\hline 11 & Puyjuni & + & + & - \\
\hline 12 & Robusta & + & + & - \\
\hline 13 & Rosada & + & + & - \\
\hline 14 & Salomé & + & - & - \\
\hline 15 & Victoria & + & + & + \\
\hline 16 & Violeta & + & + & + \\
\hline 17 & Yungueñita & + & + & - \\
\hline 18 & Jaspe & + & + & + \\
\hline 19 & Huaycha & - & - & - \\
\hline 20 & India & + & + & + \\
\hline 21 & $\mathrm{C}+$ & Pro & Pbo & Wni \\
\hline 22 & $\mathrm{C}-$ & & & \\
\hline
\end{tabular}

Leyenda: + Presencia del alelo de resistencia, - Ausencia del alelo de resistencia, C+ Control positivo (resistente), C- Control negativo (susceptible), Pro: Papa Rosa, Pbo: Pinta Boca, Wni: Wallpa Ningri. 
Revista Latinoamericana de la Papa 22 (2): 10 - 32

\section{Detección del gen de resistencia $R y_{a d g}$ al virus PVY con el marcador RySC3}

El análisis realizado mostró que el alelo para el marcador RySC3 está colocalizado con el gen $R y_{a d g}$ para resistencia a PVY, ubicada en el cromosoma XI a $320 \mathrm{pb}$ (Gebhardt et al., 2006), fue observado en todos los cultivares (Tabla 10 y Figura 2), a excepción del cultivar Huaycha que fue el control negativo (C-) donde no se observó la banda del alelo de resistencia; en cambio, el cultivar Papa Rosa (adg) que se utilizó como control positivo $(\mathrm{C}+)$ si mostró el alelo.

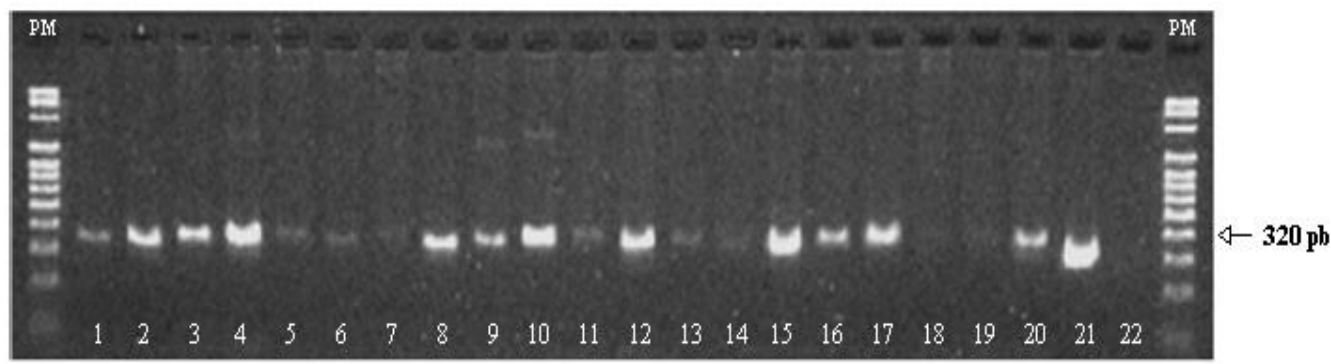

Figura 2. Detección del gen $R y_{a d g}$, utilizando el marcador RySC3 en cultivares de papa mejorada (Solanum tuberosum), representada por el fragmento de 320 pb.1. Aurora, 2. Chota Nawi, 3. Desireé, 4. Isabel, 5. Runa Toralapa, 6. Keila, 7. Morita, 8. Pafrita, 9. P'alta Chola, 10. Pinker, 11. Puyjuni Imilla, 12. Robusta, 13. Rosada, 14. Salome, 15. Victoria, 16. Violeta, 17. Yungueñita, 18. Jaspe, 19. Huaycha C-, 20. India, 21. Papa Rosa C+, C(de reacción).

\section{Detección del gen/QTL de resistencia RGp5-vrnHC}

El alelo para el marcador $\mathrm{HC}$ que colocaliza con el gen/QTL RGp5-vrnHC para resistencia a $G$. pallida, ubicado en el cromosoma V a $276 \mathrm{pb}$ (Sattarzadeh et al., 2006), no se detectó en las cultivares Desirée, Runa Toralapa, Pafrita, Pinker, Salomé y Huaycha (Tabla 10 y Figura 3). Todas las demás cultivares si mostraron el alelo de resistencia, incluyendo el control positivo Pinta Boca (stn). 
Revista Latinoamericana de la Papa 22 (2): 10 - 32

http://www.papaslatinas.org/revista.html

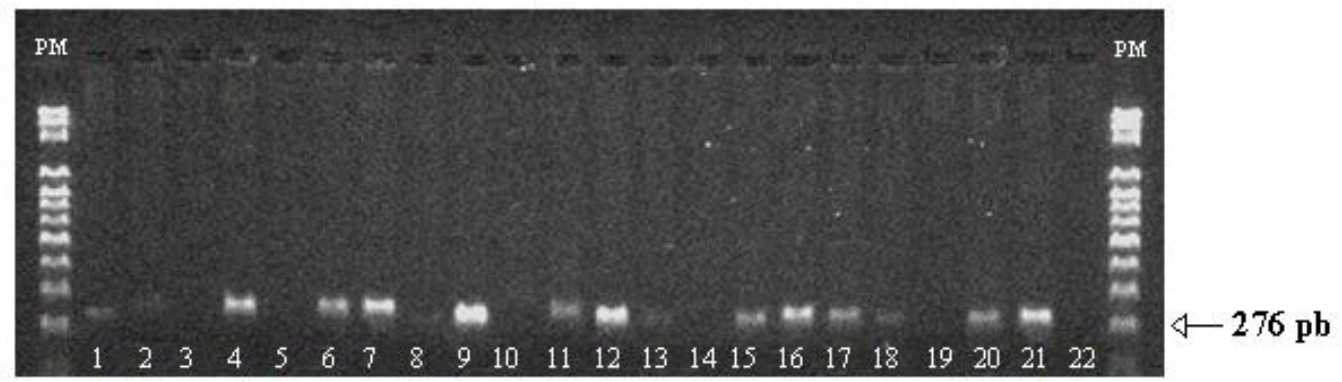

Figura 3. Detección del gen/QTL RGp5-vrnHC, utilizando el marcador $\mathrm{HC}$ en cultivares de papa mejorada, representada por el fragmento de 276 pb.1. Aurora, 2. Chota Nawi, 3. Desireé, 4. Isabel, 5. Runa Toralapa, 6. Keila, 7. Morita, 8. Pafrita, 9. P'alta Chola, 10. Pinker, 11. Puyjuni Imilla, 12. Robusta, 13. Rosada, 14. Salome, 15. Victoria, 16. Violeta, 17. Yungueñita, 18. Jaspe, 19. Huaycha C-, 20. India, 21. Pinta Boca C+, C- (de reacción).

\section{Detección del gen de resistencia Gro1-4}

El alelo para el marcador Gro1-4 que colocaliza con el gen Grol-4 para resistencia a $G$. rostochiensis en el cromosoma VII a 602 pb (Gebhardt et al.,
2006), fue observado en los cultivares Chota Nawi, Isabel, Keila, Victoria, Violeta, Jaspe e India y en el control positivo nativo Wallpa Ningri (stn). Los demás cultivares no mostraron el alelo de resistencia (Tabla 2 y Figura 4).

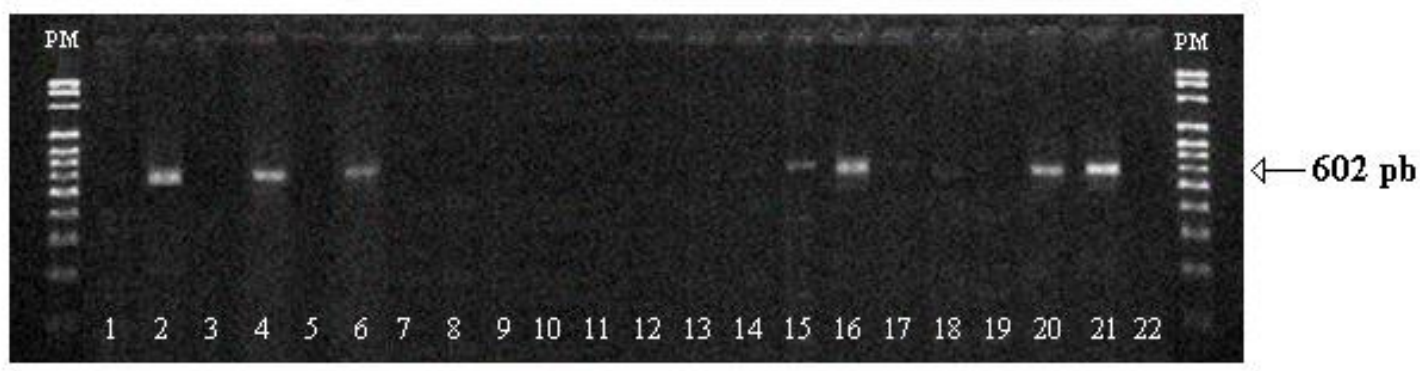

Figura 4. Detección del gen Gro 1-4, utilizando el marcador Gro 1-4 en cultivares de papa mejorada (Solanum tuberosum), representada por el fragmento de 602 pb. 1. Aurora, 2. Chota Nawi, 3. Desireé, 4. Isabel, 5. Runa Toralapa, 6. Keila, 7. Morita, 8. Pafrita, 9. P'alta Chola, 10. Pinker, 11. Puyjuni Imilla, 12. Robusta, 13. Rosada, 14. Salome, 15. Victoria, 16. Violeta, 17. Yungueñita, 18. Jaspe, 19. Huaycha C-, 20. India, 21. Wallpa Ningri C+, C- (de reacción).

En el presente estudio se validaron marcadores moleculares que co-localizan con genes de resistencia al PVY y al nematodo-quiste (G. pallida, $G$. rostochiensis) en los cromosomas XI, V y VII respectivamente. Estos marcadores fueron validados en cultivares de papa obtenidas de la combinación de diversas especies cultivadas y silvestres de papa (Gabriel et al., 2011). Las especies cultivadas utilizadas en los cruzamientos involucraron a Solanum andigena $(4 \mathrm{x}), S$. tuberosum (4x), S. goniocalyx (2x), $S$. phureja (2x) y $S$. ajanhuiri (2x), y a las especies silvestres $S$. stoloniferum (4x), $S$. 
iopetalum (6x), S. palustre (2x), S. fendleri $(2 \mathrm{x})$.

Los resultados mostraron que los marcadores moleculares utilizados para asociar los genes de resistencia a múltiples factores fue un método eficiente para asociar con los rasgos de resistencia en las cultivares evaluadas. La utilización de los marcadores ligados a los tres loci mayores de resistencia: HC, Gro 1-4 y RySC3 lograron asociarse con los genes de resistencia RGp5-vrnHC, Gro 1-4 y $R y_{\text {adg }}$ respectivamente.

Se debe mencionar que la resistencia al virus PVY es simple y está gobernada por genes $\mathrm{R}$ mayores que le confiere un tipo de resistencia monogénica (Mihovilovich et al., 1998; Fernández - Northcote, 1991). Esto se notó en los 20 cultivares, o sea el $100 \%$ mostró la presencia del alelo de resistencia a PVY, probablemente proveniente de las especies de $S$. andigena y/o S. stoloniferum (FernándezNorthcote y Brown, 1981), utilizados en la generación de los cultivares. Una experiencia reciente en la que se utilizó el marcador RySC3 para la detección del gen $R y_{a d g}$, de un total de 71 progenitores de papa analizados, 30 mostraron algún tipo de resistencia a PVY y 17 fueron portadores del marcador; además este marcador fue utilizado para la selección asistida (SAM) en 499 progenies provenientes de diferentes cruzamiento, mostrando un $99.7 \%$ en la eficacia de detección del gen $R y_{a d g}$ (Sagredo et al., 2009).

En el caso del nematodo del quiste el análisis de la resistencia se complica por ser poligénica y está gobernada por genes menores de herencia cuantitativa (Ross, 1986). En el presente estudio se observó que 14 de las 20 cultivares evaluados, es decir el $70 \%$ mostraron el alelo de resistencia para G. pallida y 7 de los 20 cultivares, es decir el $35 \%$ mostraron el alelo de resistencia a $G$. rostochiensis Esto, está indicando la complejidad de la resistencia de $G$. rostochiensis en referencia a $G$. pallida. Esta resistencia aparentemente está vinculada a la especie $S$. palustre (antes $S$. vernei) y $S$. andigena, que fueron reportadas como resistentes por Ross (1986) y que fueron utilizadas en las cruzas para obtener los cultivares evaluados.

Se debe resaltar que los cultivares nativos Papa Rosa (adg), Pinta Boca (stn) y Wallpa Ningri (stn) mostraron ser testigos positivos para los marcadores moleculares RySC3, HC y Gro 1-4, que están asociados a los genes de resistencia a PVY, G. pallida y $G$. rostochiensis. Indicando esto que estas especies son una nueva fuente de resistencia genética, y que no fueron reportados antes como resistentes.

Se debe enfatizar que sólo se puede diferenciar genes/QTL seleccionables. Esto requiere que tanto el marcador sea polimórfico, como que la configuración alélica del gen/QTL sea apropiada (Gabriel 2008).

Fue notorio observar que existen marcadores indirectos y directos. En los marcadores indirectos hay ciertas distancias entre el marcador y un gen de interés y puede haber recombinaciones. A este tipo de marcadores pertenecen los SSRs que son muy polimórficos pero se pueden también seleccionar "falsos alelos", debido a las recombinaciones. Esto requiere aumentar el número de SSRs disponibles (Gabriel 2008).

Análisis de resistencia al virus $Y$ de la papa (PVY)

El test DAS-ELISA mostró datos de absorbancia y severidad al virus PVY que no se ajustaron a una distribución normal para su análisis de varianza, por lo que se transformaron los datos con una función raíz cuadrada, logrando de esta forma 
ajustar a una curva normal. El coeficiente de varianza fue de $9.94 \%$ y $32.56 \%$ respectivamente. Indicando esto que la varianza está en el rango permitido para este tipo de experimentos. (Tabla 11). EL ANOVA mostró que hubo diferencias significativas al $\mathrm{p}<0.05$ de probabilidad para cultivares, lo que indicó que al menos una cultivar fue diferente en la absorbancia y la severidad al virus PVY (Tabla 11).

Tabla 11. ANOVA de las variables absorbancia y severidad del virus PVY.

\begin{tabular}{cccc}
\hline FV & Gl & CM abs & CM sev \\
\hline Cultivares & 20 & $0.04^{*}$ & $0.97^{*}$ \\
Error & 59 & 0.02 & 0.46 \\
Total & 79 & & \\
\hline CV & & 9.94 & 32.56 \\
\hline
\end{tabular}

Leyendas: FV: Fuentes de Variación, Gl: Grados de Libertad, CM: Cuadrados Medios, CV: Coeficiente de Variación, *: significativo al $\mathrm{p}<0.05$.

El análisis de medias mediante la prueba de Duncan, mostró que la absorbancia para el virus PVY fue significativamente diferente $(p<0.05)$ para las cultivares evaluados, esto estaría indicando que el comportamiento frente al virus PVY no es el mismo en todos los cultivares. Se determinaron ocho grupos de resistencia (Figura 5). El cultivar que presentó mayor resistencia fue Chota Nawi, seguida por la resistencia de Aurora, Desireé y Victoria. Los cultivares Huaycha y Runa Toralapa mostraron resistencia moderada. Los cultivares P'alta Chola, Isabel, Robusta, Keila, Violeta, Pinker, India, Yungueñita, Salomé y Rosada mostraron resistencia parcial. Las cultivares Puyjuni imilla, Morita y Jaspe fueron moderadamente susceptibles y la más susceptible fue el cultivar Pafrita.

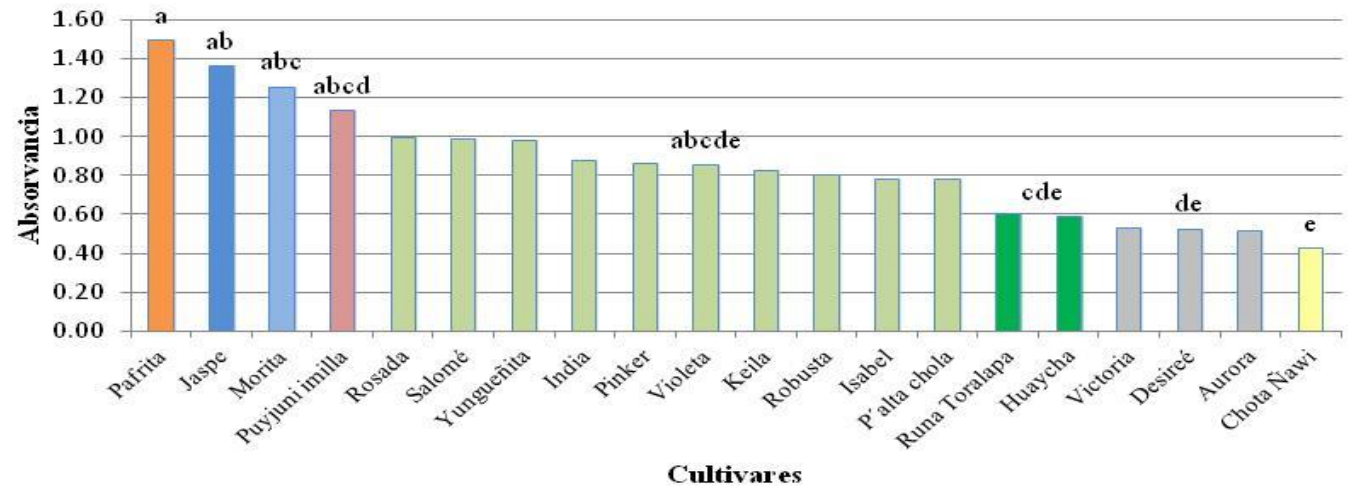

Figura 5. Histograma de los valores promedio de absorbancia del virus PVY en las 20 cultivares de papa. Promedios con letras distintas indican diferencias significativas al $\mathrm{p}<0.05$ de probabilidad. Valor DMS $=.6111$

En cuanto a severidad se determinaron cinco grupos de resistencia (Figura 6) siendo el cultivar Victoria con mayor resistencia. Luego P’alta Chola, Huaycha, 
Isabel, Violeta, Chota Ñawi, Pinker, Keila, Robusta e India mostraron resistencia moderada. Los cultivares Puyjuni imilla, Aurora, Yungueñita, Jaspe, Desireé y Salomé con resistencia parcial. Los cultivares Morita, Rosada y Pafrita fueron moderadamente susceptibles y el cultivar Runa Toralapa fue el más susceptible al virus PVY (Figura 6).

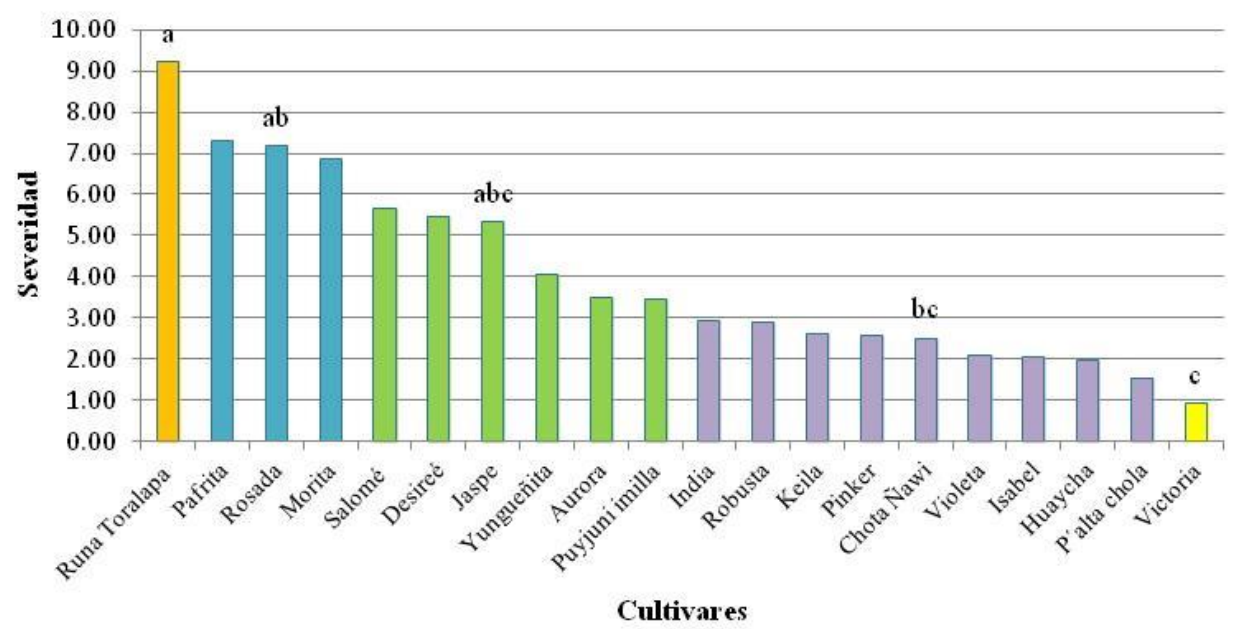

Figura 6. Histograma de los valores promedio de severidad del virus PVY en los 20 cultivares de papa. Valor DMS $=4.445$

Los cultivares Chota Nawi y Victoria fueron reportadas como resistentes al virus PVY en evaluaciones de campo previas como fue señalado por Gabriel $e t$ al. (2011) y comprobado en este experimento, debido probablemente a la inmunidad a PVY en S. stoloniferum y la subsp. andigena las cuales son gobernadas por genes dominantes Rysto y Ryadg respectivamente según indica Fernández-Northcote (1991) y Flis et al. (2005). Por otro lado el cultivar Pafrita no fue registrado como resistente en previas evaluaciones de campo y de acuerdo a los datos de absorbancia y severidad es el cultivar más afectado por el virus. Los tres cultivares amplificaron para el marcador RySC3.

El análisis de correlación de Pearson entre las variables Absorbancia y Severidad mostró una baja correlación $(\mathrm{r}=0.251)$, significativa a un $\mathrm{p}<0.05$ de probabilidad.
La baja correlación entre la absorbancia y los datos de severidad del virus PVY en las cultivares evaluadas, podría deberse a distintos factores, como el enmascaramiento de síntomas teniendo en cuenta que el desarrollo de síntomas depende del huésped, del virus y de las condiciones ambientales. Por eso uno espera encontrar plantas susceptibles que no muestran síntomas. Por otro lado debido a la presencia de algún otro virus que esté co-existiendo con el virus PVY, el cual no podía ser detectado mediante DAS-ELISA por la especificidad de esta prueba. Se conoce que las interacciones entre virus (sinergismo) pueden inducir el desarrollo de enfermedades más severas que aquellas causadas por la infección con un solo virus como menciona Salazar (1995). Este último es menos probable ya que el experimento con virus se realizó bajo condiciones controladas en invernadero. 


\section{Análisis de resistencia al nematodo quiste Globodera spp.}

La Tasa de multiplicación en raíz (TMR), Tamaño de raíz (TR) y Peso de raíz (PR) no mostraron una distribución normal por lo que se transformaron los datos aplicando la función $\log (\mathrm{n}+1)$ para ajustar a una curva normal. Se observó CV de 27\%, $19 \%$ y $19 \%$ respectivamente. Esto estaría indicando que la varianza está en el rango permitido para este tipo de experimentos. La prueba de ANOVA mostró diferencias significativas a una probabilidad de $p<0.05$ para PR. Indicando esto que al menos una cultivar mostró diferencias en PR. No se observaron diferencias significativas para TMR y TR (Tabla 13).

Tabla 13. ANOVA de la Tasa de multiplicación en raíz (TMR), Tamaño de raíz (TR) y Peso de raíz (PR) en las 20 cultivares evaluados.

\begin{tabular}{ccccc}
\hline FV & Gl & CM TMR & CM TR & CM PR \\
\hline Cultivares & 19 & $0.36 \mathrm{~ns}$ & 0.10 & $0.09 *$ \\
Error & 64 & 0.23 & 0.13 & 0.05 \\
Total & 83 & & & \\
CV & & 27.02 & 19.07 & 19.08 \\
\hline
\end{tabular}

Leyendas: FV: Fuentes de Variación, Gl: Grados de Libertad, CM: Cuadrados Medios, CV: Coeficiente de Variación, Pr: Probabilidades, *: Significativo al p<0.05 de probabilidad.

El análisis de medias mediante la prueba de Duncan con TMR, determinó siete grupos diferentes de resistencia (Figura 9): El cultivar P'alta Chola con mayor resistencia, seguida por la resistencia de Salomé y Pinker. Los cultivares Chota Ñawi, Desireé y Robusta mostraron resistencia moderada. Se observó una resistencia parcial en los cultivares Isabel, Rosada, Runa Toralapa, Yungueñita, Aurora, Puyjuni Imilla, Victoria, Morita, India, Keila y Jaspe. El cultivar Huaycha fue moderadamente susceptible y los cultivares Pafrita y Violeta fueron los más susceptibles a la infección por nematodos del quiste.

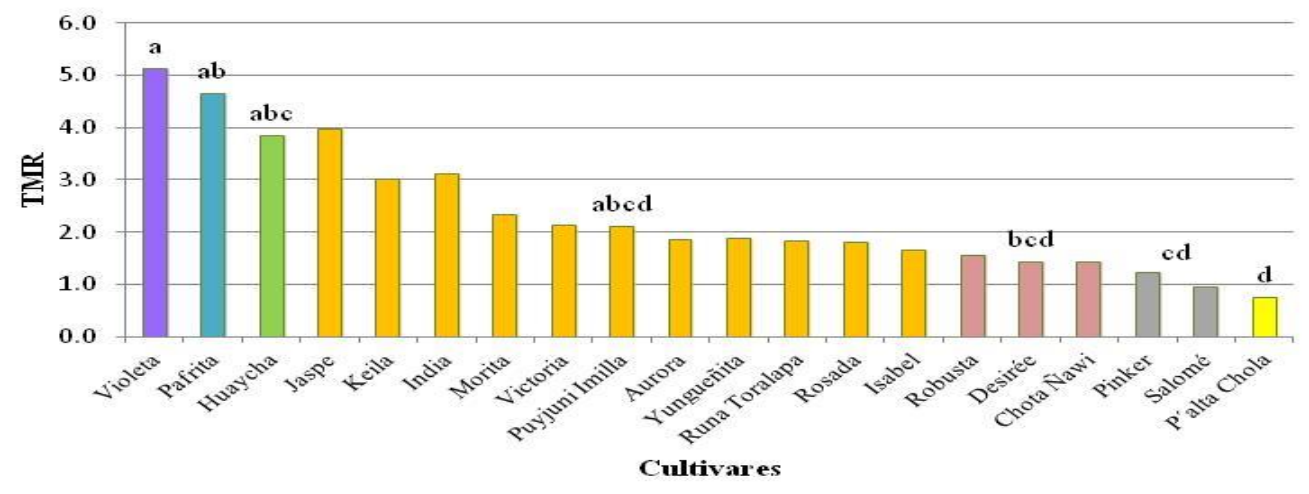

Figura 7. Histograma de los valores promedio de TMR para las 20 cultivares de papa. Valor DMS $=2.741$ 
Revista Latinoamericana de la Papa 22 (2): 10 - 32 http://www.papaslatinas.org/revista.html El cultivar P'alta Chola fue reportada como resistente a Globodera spp. por Gabriel et al., (2011) en previos estudios de campo, lo cual se pudo comprobar en el presente estudio ya que fue la cultivar que presentó la menor TMR. Este cultivar amplificó para el marcador HC. En los cultivares Violeta y Pafrita se expresaron los mayores TMR, confirmando ambos cultivares su susceptibilidad al ataque de los nematodos del quiste. El cultivar Violeta amplificó los marcadores HC y Gro 1-4, sin embargo el cultivar Pafrita no amplificó para ninguno de los marcadores.

El análisis de correlación de Pearson para las variables TMR, TR y PR (Tabla 14), mostró una correlación moderada $\mathrm{y}$ altamente significativa a un $\mathrm{p}<0.01 \mathrm{de}$ probabilidad $(r=0.443)$ entre el TMR y el TR, una baja correlación $(r=0.312)$ entre TMR y PR, finalmente una alta correlación y altamente significativa $(\mathrm{r}=$ 0.631) entre TR y PR.

Franco et al. (1993) menciona que, el concepto de resistencia a $G$ rostochiensis y G. pallida, en la mayoría de clones de papa, está relacionado a la falta de desarrollo del segundo estado juvenil (J2) después de penetrar a la raíz, o de ser posible el desarrollo, hay preferencia a formarse machos en mayor proporción. El exudado radicular asegura que los nematodos (J2) emerjan del huevo cuando las condiciones son favorables y se produzca la penetración a la raíz, seguido esto numerosos cambios bioquímicos deben ocurrir en el metabolismo de la planta como consecuencia de su compatibilidad (susceptibilidad) o como resultado de su incompatibilidad (resistencia) durante el proceso de relación hospedante-parásito, esto sugiere que un mayor desarrollo radicular permite una mayor invasión, desarrollo y

multiplicación del nematodo del quiste. En este caso la tasa de multiplicación del nematodo en raíz (TMR) no tiene una fuerte correlación con el tamaño (TR) y peso de raíz (PR) sino una moderada y baja correlación, lo cual indica que la reproducción del nematodo se ve afectada no solo por la cantidad de raíz sino por diversos factores como la resistencia que posea la cultivar de papa, las condiciones del medio ambiente y la raza o patotipo del nematodo.

Las razas o patotipos del nematodo del quiste podrían complicar el análisis de la resistencia. En ambas especies de Globodera se presentan varios patotipos, los cuales pueden llegar a superar la resistencia por ejemplo, un cultivar de papa reconocida como resistente puede llegar a estar infestada por un número cada vez mayor de poblaciones de nematodos debido a la selección y multiplicación de otros patotipos de Globodera (Franco, 1981). En nuestro estudio el marcador HC reportado por Sattarzadeh et al., (2006) detecta el gen de resistencia a G. pallida específicamente para los patotipos Pa2/Pa3, y el marcador Gro 1-4 reportado por Gebhardt et al., (2006) detecta el gen de resistencia a $G$. rostochiensis para los patotipos 1-4. A nivel mundial se han identificado cinco patotipos de $G$. rostochiensis y seis de $G$. pallida, por tanto los marcadores utilizados pueden no estar detectando todos los patotipos presentes en la población de nematodos, esto podría explicar el que algunos cultivares evaluados a pesar de haber amplificado ambos marcadores hayan presentado altos niveles de multiplicación del nematodo.

Es el complejo de poblaciones del nematod del quiste lo que dificulta una mayor precisión en el análisis, además es conocido que $G$. rostochiensis es 
manejado por un gen, en cambio $G$. pallida es poligénico, eso complica más el tipo de marcadores usados, fuera de las razas y especies (Achenbach, 2007). Sin embargo este trabajo contribuye al conocimiento de nematodos en Bolivia.

La identificación de especies de Globodera realizada a través de cortes perineales en quistes, determinó que en todos los casos hubo predominancia de la población de $G$. pallida en las cultivares evaluados, es decir G. pallida $(86.25 \%$ aproximadamente) supera en porcentaje de quistes a $G$. rostochiensis (13.75\% aprox.) (Tabla 15).

Tabla 15. Determinación de especies de Globodera en muestras de los cultivares evaluados.

\begin{tabular}{|c|c|c|c|}
\hline \multirow{3}{*}{ Cultivar } & \multirow{3}{*}{$\begin{array}{c}\begin{array}{c}\text { Cortes } \\
\text { perineales }\end{array} \\
\text { Repetición }\end{array}$} & \multicolumn{2}{|c|}{ Población } \\
\hline & & \multirow{2}{*}{$\begin{array}{l}\text { G. rostochiensis } \\
\text { (porcentaje) }\end{array}$} & \multirow{2}{*}{$\begin{array}{c}\text { G.pallida } \\
\text { (porcentaje) }\end{array}$} \\
\hline & & & \\
\hline \multirow{2}{*}{ Pafrita } & 1 & 20.0 & 80.0 \\
\hline & 2 & 25.0 & 75.0 \\
\hline \multirow{2}{*}{ Rosada } & 1 & 21.4 & 78.6 \\
\hline & 2 & 15.4 & 84.6 \\
\hline \multirow{2}{*}{ Huaycha } & 1 & 29.4 & 70.6 \\
\hline & 2 & 16.7 & 83.3 \\
\hline \multirow{2}{*}{ Runa Toralapa } & 1 & 18.2 & 81.8 \\
\hline & 2 & 10.0 & 90.0 \\
\hline \multirow{2}{*}{$\mathrm{P}^{\prime}$ alta Chola } & 1 & 8.3 & 91.7 \\
\hline & 2 & 27.3 & 72.7 \\
\hline \multirow{2}{*}{ India } & 1 & 0.0 & 100.0 \\
\hline & 2 & 21.4 & 78.6 \\
\hline Promedio & & 13.75 & 86.25 \\
\hline
\end{tabular}

Franco y González (2011) reportaron que en Bolivia, G. pallida supera ligeramente la incidencia de $G$. rostochiensis. Chuquisaca, La Paz y Cochabamba son los Departamentos más infestados por esta especie, en cambio, Tarija y La Paz por G. rostochiensi, en este caso en particular se comprobó la predominancia de la población de $G$. pallida por sobre $G$. rostochiensis en las muestras evaluadas.

\section{Agradecimientos}

Este trabajo fue desarrollado por la Fundación PROINPA, en el Proyecto "Fontagro - Clipapa". Las opiniones expresadas en el mismo no reflejan necesariamente la opinión oficial de estas instituciones. Asimismo, Los autores agradecen la colaboración del Dr. Javier Franco, Ing. MSc. Noel Ortuño e Ing. MSc. Giovanna Plata por sus acertadas sugerencias y contribuciones en el análisis de laboratorio.

\section{Conflictos de intereses}

El presente documento no presenta conflictos de intereses.

\section{Referencias citadas}

Alarcón, J. (2008). Validación de marcadores moleculares asocidos a QTL's (quantitative trait loci), para su aplicación agroindustrial en papas bolivianas. Tesis de grado para optar al título de licenciatura en Ingenieria 
agroindustrial, UMSS. Cochabamba, Bolivia.

Achenbach, U. (2007). Identification and Characterization of Quantitative Trait Loci (QTL) for Resistance to the Cyst Nematode (Globodera pallida) in the Potato (Solanum tuberosum). $42 \mathrm{pp}$.

Canto-Sáenz, M.; González, A. (1993). Uso de gasolina para la separación de quistes de Globodera pallida y materia orgánica en muestras extraídas de suelo. Nematropica 23(1):57-61.

Cervantes, R. (2010). Plaguicidas en Bolivia: sus implicaciones en la salud, agricultura y medio ambiente. Revista Virtual REDESMA v.4 n.1. La Paz. Disponible en http://www.revistasbolivianas.org.bo/sciel o.php (Agosto, 2014)

Chávez, R. (2007). Sobre el origen, evolución y diversidad genética de la papa cultivada y la silvestre. Revista Ciencia y Desarrollo. Vol. 10: 111-117.

CIP (1996) Principales enfermedades, nematodos a insectos de la papa. Limaperú. $22,32 \mathrm{pp}$.

Coca, M. (2012). Una mirada al cultivo de la papa en Bolivia. CochabambaBolivia. 8 pp. En: http://www.cebem.org/cmsfiles/articulos/ Una_mirada_al_cultivo_de_la_papa_en Bolivia.pdf (Septiembre, 2014)

Coca, J. (2010). Cultivares nativas de papa (Solanum tuberosum L.) evaluadas por su reacción de resistencia y/o susceptibilidad a factores bióticos y abióticos. Tesis de grado para optar al título de licenciatura en Biología. Universidad Mayor de San Simón. Cochabamba-Bolivia.

Devaux, A.; Ordinola, M. (2012). De América para el mundo. Revista Papa 26: 16-18.
Doyle, J.J.; Doyle J.L. (1990). Isolation of DNA from small amounts of plant tissues. BRL Focus 12: 13-15.

Estrada, N. (2000). La biodiversidad en el mejoramiento genético de la papa. PROINPA, CID, CIP. Plural Editores. La Paz - Bolivia. 139 pp.

Fernández-Northcote, E.N.; Brown, C.R. (1981). Resistence in diploid Solanum phureja, S. stenotomun, and S. berthaultii intercrosses to potato virus Y. (Abstr.) Phytopathology 81:873.

Fernández-Northcote, E.N. (1991). Mejoramiento por resistencia a los principales virus de la papa. Revista Latinoamericana de la Papa 4:1-21.

Franco, J. (1981). Nematodos del quiste de la papa. Globodera spp. Boletín de información técnica 9. Centro Internacional de la Papa (CIP). Lima, Perú. 14 p.

Franco, J.; Gonzáles, A.; Matos, A. (1993). Manejo integrado del nematodo quiste de la papa Globodera spp. Centro internacional de la papa (CIP). Programa de investigación de la papa (PROINPA). Cochabamba, Bolivia.

Franco, J.; González, A. (2011). Pérdidas causadas por el nematodo quiste de la papa (Globodera sp.) en Bolivia y Perú. Revista Latinoamericana de la papa 16 (2): 233-249.

Flis, B.; Henning, J.; Strzelczyk-Zyta, D.; Gebhardt, C. (2005). The Ry-fsto gene from Solanum stoloniferum for extreme resistant to Potato virus $Y$ maps to potato chromosome XII and is diagnosed by PCR marker GP122 218 in PVY resistant potato cultivars. Molecular Breeding 15: 95-101.

Ford-Lloyd, B.V. (2001). Genotyping in plant genetic resources in plant genotyping : The DNA fingerprinting of 
plants.r.j.Henry (ed). Center for plant conservation genetics. Australia. 344 pp.

Gabriel, J. (2008) Aplicación de marcadores moleculares para el cribado de QTLs en diferentes fuentes de resistencia a tizón tardío (Phytophthora infestans) en papa. Tesis doctoral, Universidad Pública de Navarra (UPNA), Pamplona, España. 109 p.

Gabriel, J. (2010). Documento marco: Estrategias y perspectivas del mejoramiento genético de papa (Solanum tuberosum L.) En Bolivia. ISBN: 978-99954-743-2-4, Fundación PROINPA, Cochabamba, Bolivia. 23 p.

Gabriel, J.; Pereira, R.; Gandarillas, A. (2011). Catálogo de nuevas cultivares de papa en Bolivia. Fundación PROINPA. Cochabamba, Bolivia. Pp 25-46.

Gabriel J, Castro C, Valverde A, Indacochea B (2017) Diseños experimentales: Teoría y práctica para experimentos agropecuarios. Grupo COMPAS, Universidad Estatal del Sur de Manabí (UNESUM), Jipijapa, Ecuador. $116 \mathrm{p}$.

Gebhardt, C.;Bellin, D.; Henselewski, H.; Lehmann, W.; Schwarzfischer, J.; Valkonen, J.P. (2006). Marker-assisted combination of major genes for pathogen resistance in potato. Theor Appl Genet 112: 1458-1464.

González, A.; Franco, J. (1993). Técnicas y métodos para el nemato quiste de la papa Globodera spp. Centro internacional de la papa (CIP). LimaPerú. 80 pp.

Guzmán, F. (2010). Caracterización molecular y genética de los marcadores ligados al gen Ryadg del cromosoma XI de Solanum tuberosum ssp andigena y su aplicación en la identificación de nuevas fuentes de resistencia al virus PVY. Tesis para optar al grado académico de
Magíster en Biología Molecular. Universidad nacional Mayor de San Marcos. Lima-Perú.

Hawkes, J.G. (1978). The history of the potato. Edit. P.M. Harris, Chapman Hall. London, UK.

Hernández-González， J.L. (2007). Distribución de probabilidad de variables aleatorias discretas. Departamento de ciencias básicas. Instituto Tecnológico de Apizaco. Tlaxcala, México. Disponible en http://www.itapizaco.edu.mx/ joseluis/ap untes/estadistica/distribuciones\%20discre tas.pdf

Jiménez-Pérez, N.; Crozzoli, R.; Greco, N. (2007). Nematodos fitoparasíticos asociados con el cultivo de la papa en el Estado Lara, Venezuela. Fitopatol. Venez. 20(2):34-40.

Mendoza, H.A. (2008) Genética y Mejoramiento de la Papa en el Perú. Año internacional de la papa. Disponible en http://www.asdmas.com/documentos/curs oRAAA/primer\%20dia/Humberto.pdf

(Julio, 2008)

Mihovilovich, E.J.; Salazar, L.F.; Saguma, F; Bonierbale, M.W. (1998). Survey of the durability of extreme resistance to PVY derived from Solanum tuberosum ssp. andigena. Páginas 123128 in CIP program report 1997-1998, Lima Perú.

Mosquera, T.; Fernández, C.; Martínez, L.; Acuña, A.; Cuéllar, D. (2008). Genética de la resistencia de la papa (solanum tuberosum) a patógenos. Estado de arte. Agronomía colombiana 26(1), 715. Bogotá, Colombia.

Ortuño, N.; Franco, J.; Oros, R., Main, G. (1994). Producción de tubérculos para semilla de papa libre de nematodos. Hoja Técnica. Revista Manejo Integrado de Plagas (52). 
Ottoman, R.; Hane, D.; Brown, C., Yilma, S.; James, S.; Mosley, A.; Crosslin, J.; Vales, M.I. (2009). Validation and Implementation of Marker-Assisted Selection (MAS) for PVY Resistance (Ryadg gene) in a Tetraploid Potato Breeding Program. Am. J. Pot Res 86:304-314.

Ross, H. (1986) Potato BreedingProblems and Perspectives. Verlaug Paul Parey, Berlin and Hamburg, 132 p.

Salazar, L.F. (1995). Los virus de la papa y su control. Centro Internacional de la Papa (CIP). Lima, Perú. 226 p.

Sagredo, B.; Matías, M.; Barrientos, C.; Acuña, I.; Kalazich, J.; Santos-Rojas, J. (2009) Evaluation of a scar RySC3 marker of the Ryadg gene to select resistant genotypes to potato virus y (pvy) in the INIA potato breeding program. Ch. J. Agr. Res. 3 (69): 305 - 315.
SAS (2004). The SAS system. Version 9.2. SAS OnlineDoc. HTML. Format, SAS Institute, Cary, NC, USA.

Sattarzadeh, A.; Achenbach, U.; Lübeck, J.; Strahwald, J.; Tacke, E., Hofferbert, H.; Rothsteyn, T.; Gebhardt, C. (2006). Single nucleotide polymorphism (SNP) genotyping as basis for developing a PCR-based marker highly diagnostic for potato varieties with high resistance to Globodera pallida pathotype Pa2/3. Mol Breeding 18:301-312.

Sosa-Moss, C.; Perdomo, F.; Brathwait, C.; Salazar, J. (1997). Técnicas para el diagnóstico de las enfermedades de las plantas: Diagnóstico fitosanitario. Instituto Interamericano de cooperación para la agricultura (IICA). México. pp 163,164, 177-181.

Zeballos, H.; Balderrama, F.; Condori, B.; Blajos, J. (2009). Economía de la papa en Bolivia (1998-2007). Fundación PROINPA, Cochabamba, Bolivia. 129 p. 